\title{
Research on slope support technology based on fast drainage
}

\author{
Meng-yun Mao ${ }^{1,2, \text { a, Yao Rong }}{ }^{1,}$ Chun-yang Wang ${ }^{3,}$ Bing Sun ${ }^{3,}$ \\ 1 Jiangxi Transportation Institute, Jiangxi Nanchang, 330200, China \\ 2 Jiangxi Agriculture University, Jiangxi Nanchang, 330045, China \\ ${ }^{3}$ Chongqing Jiaotong University, Chongqing, 400074, China \\ a13707011206@163.com
}

Keywords: Slope reinforcement; drainage technology; slope support

Abstract. With the rapid development of China's economic construction, construction, water conservancy, mining, railway, highway, etc. are also changing rapidly, the number of high slope gradually increased; the scale is also expanding, so the slope reinforcement technology of cognition and use is very important. In this paper, through the analysis of specific examples of slope, analysis of the main reasons for the occurrence of slope instability, in the summary and analysis of the existing advantages and disadvantages of the existing slope reinforcement technology, based on the improvement of slope support technology, to provide reference for similar projects.

\section{Introduction}

China is a vast and mountainous country, the ratio of the mountainous area accounts for the national total area of up to $2 / 3$. Along with the traffic and water conservancy in our country, the quantity of slope is more and more. Due to the limitation of terrain, mountain area highway and hydropower project construction often form high slope. If the slope is not in a timely and effective support and reinforcement, it will appear the phenomenon of instability, to the construction and safety of major threats, resulting in large economic losses and even casualties.

The highway project, the slope treatment is the focus and difficulty of Subgrade in engineering construction. Early road construction mainly to low highway, traffic flow, roadbed digging and filling less, slope disaster is not prominent, and slope reinforcement door did not get enough attention [1]. With the demand of economic development in our country, the highway construction is booming, the grade of the highway is increasing, and the high slope is increasing. The protection and reinforcement of the highway is becoming the key project in the highway construction.

In this paper, the authors review the literature on slope stability and support design during the period of 2000 2015, and summarize some typical examples of slope failure and design. The occurrence of many slope instability accidents shows that there are great safety hidden danger in the construction of highway, hydropower station, and many types of slope reinforcement technology, and some of the reinforcement of the stability of the slope, so the analysis of the reasons of slope failure, summarize the advantages and disadvantages of each reinforcement program, improve the support technology is necessary.

\section{Engineering example analysis}

I will consult the slope treatment case points for three categories [2-13]: (1) Highway cut slope design scheme, such as the use of ecological protection and masonry protection and so on. (2) Reinforced design examples of the high slope of the hydropower station, as shown in table 1. (3) Design of new support after slope failure, as shown in table 2. 
Table 1 Example of reinforcement design for high slope of hydropower station

\begin{tabular}{|c|c|c|}
\hline & Name of side slope & Situation \\
\hline 1 & $\begin{array}{c}\text { Two family Hydropower } \\
\text { Station slippery stone bedding } \\
\text { rock slope }\end{array}$ & $\begin{array}{l}\text { (1)The earthquake reduced the formation of landslide, the } \\
\text { tensile area side force and trailing edge tension.(2)After the } \\
\text { earthquake, rainfall, slope of central crack, lower olistostrome. } \\
\text { On the bottom of the slope and the middle part of the } \\
\text { prestressed anchor cable }+3 \text { shear hole reinforcement. }\end{array}$ \\
\hline 2 & $\begin{array}{c}\text { The high slope of Dagangshan } \\
\text { Hydropower Station }\end{array}$ & $\begin{array}{l}\text { (1)In addition, the resistance sliding rock mass of the outlet of } \\
\text { the fault shear is excavated, and the stability condition of the } \\
\text { slope is deteriorated.(2)The excavation blasting vibration, the } \\
\text { slope groundwater appeared cracks occur, the sliding traction } \\
\text { tensile failure. Using anti shear hole, anchorage hole. }\end{array}$ \\
\hline
\end{tabular}

\section{Table 2 Design examples of support after slope failure}

\begin{tabular}{|c|c|c|}
\hline & Name of side slope & Situation \\
\hline 1 & $\begin{array}{l}\text { Ten day high speed Ankang } \\
\text { section K57+265 K57+325 }\end{array}$ & $\begin{array}{l}\text { Weathered phyllite, fissures, excavation and heavy rainfall, the } \\
\text { whole surface slip failure, frontal slope right part occurred pile } \\
\text { collapse failure. Four level to six support. }\end{array}$ \\
\hline 2 & $\begin{array}{l}\text { Guiliu high-speed } \\
\text { K444+712-822 }\end{array}$ & $\begin{array}{l}\text { Slope down blocked longitudinal bending deformation and } \\
\text { fracture surface, lots of local rock crushing, accompanied with } \\
\text { the infiltration of precipitation occurrence of slip - bending } \\
\text { failure. The use of prestressed anchor, with bolt, patching, } \\
\text { supporting net, the drain hole, repair summer ditch. }\end{array}$ \\
\hline 3 & $\begin{array}{l}\text { The left side slope of K110+ } \\
778 \sim \text { K110+ } 960 \text { section of the } \\
\text { plum river highway }\end{array}$ & $\begin{array}{l}\text { (1) The adjustment of stress, the relaxation of the slope and the } \\
\text { deformation of the ditch. Prestressed anchor cable.( } 2 \text { ) } \\
\text { Continuous rainfall to the overall decline in the slope, the } \\
\text { sliding range of all the slope reinforcement works all damage. } \\
\text { The prestressed anchor cable and steel pipe combination. }\end{array}$ \\
\hline 4 & $\begin{array}{l}\text { The roadbed side slope of the } \\
\text { coal measure strata in the } \\
\text { expressway }\end{array}$ & $\begin{array}{l}\text { During the rainy season, the traction sliding of the soft layer is } \\
\text { adopted, and the anchor rod and the anti slide pile are used. }\end{array}$ \\
\hline
\end{tabular}

\section{The reason analysis of slope failure}

There are many factors that affect the slope stability, which can be summarized as the slope shape, the geological condition, the external environment and so on.

Slope of the geometric elements of the main high slope, slope angle, slope yield, geometry and size of the slope size and so on.

The geological conditions that affect the stability of the slope include: rock properties, structural characteristics and mechanical properties of the structural plane.

External environment is the impact of the external environment surrounding the slope geological body, which has a lot of factors, including climate characteristics, human activities, surface vegetation cover, seismic activity, and so on.

According to the above examples, it can be found that the improper excavation method and heavy rainfall are the main factors to induce the slope failure. Most of the slope failure is caused by heavy rain or continuous rain. Before these slopes are not without reinforcement, once again the failure of the slope again let us once again Alert: select the appropriate reinforcement measures conducive to the rapid drainage of drainage measures is essential. 


\section{The application of several kinds of slope reinforcement technology and the improvement of drainage technology}

Slope treatment is a disaster prevention and control project with complicated technology and difficult construction. Main measures of slope cutting load shedding, drainage and cut-off measures, anchorage measures, and concrete shear structural measures and supporting measures, measures of slope and plant latticework slope protection, facing pressure etc. In order to strengthen the stability of the slope, the principle of comprehensive treatment of multiple measures is emphasized in the engineering of slope reinforcement.

Drainage is an important measure in the slope reinforcement engineering. Drainage system including surface drainage works and underground drainage works. Surface drainage is in order to maximize the rain from the surface to the surface, to prevent infiltration into the slope, including the layout of the slope and the slope of the ditch and pipelines, etc. Underground drainage is to reduce the height of the water table which has been formed in the slope, and can use the drainage gallery and the drainage hole.

Block wall supporting structure as a gravity type structure, the drainage measures is mainly the scuppers. In case of heavy rainfall or prolonged rainfall can be problems, it is suggested that fast drainage by comprehensive drainage measures. The discharge hole + concentrated drainage tube, as shown in Figure. 1 to rapid drainage, prevent a wall of water to the wall to bring additional hydrostatic pressure.

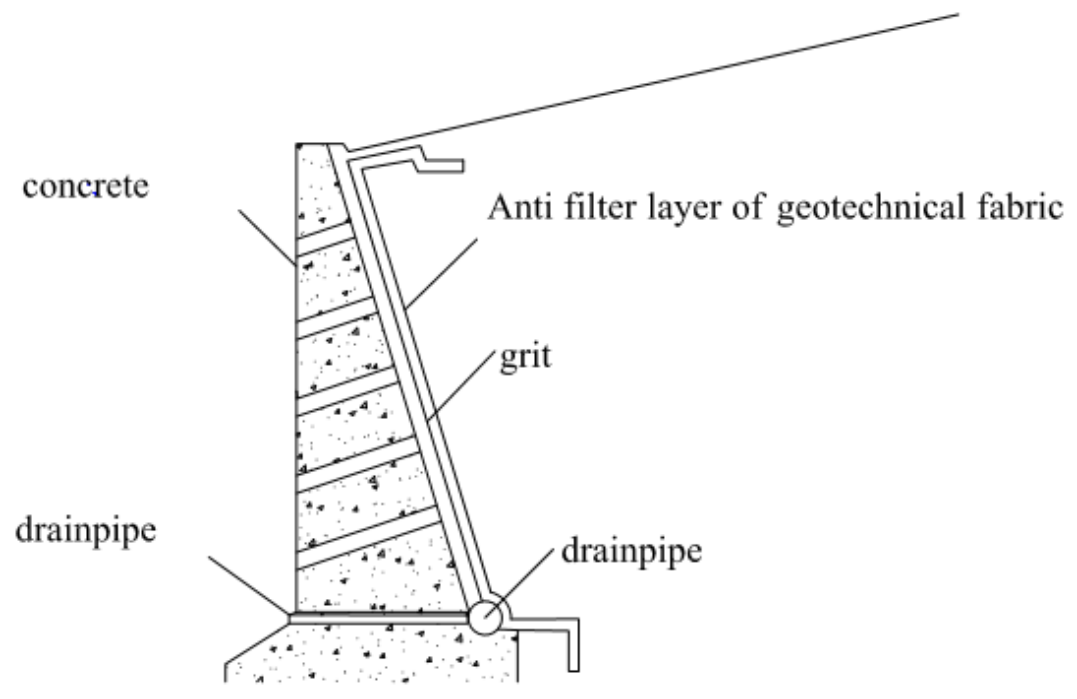

Figure. 1 retaining wall drainage hole, drainage tube distribution map

Prestressed anchor cable frame beam support increases the integrity of the slope, so that it can better stress, and in the case of vegetation to protect the slope to better follow the principles of building green ecological slope. Its application in soil surface can't bear cable transfer to the anchoring force of frame beam, such as the surface is weak, loose, moist soil, you cannot use this scheme; lots of anchor cable unable to provide enough anchoring force of slope, such as anchorage for organic soil, silty soil, or formation of reinforced concrete has strong corrosion of the slope, also cannot use this support scheme.

Drainage of slope support schemes for such general considerations: (1) setting the drains, in order to rapid drainage must be taking into account the water is too hasty to ditch erosion and drainage ditch silting problems, so when the water is urgent to the trench wall to take protective measures, longitudinal slope should not be less than $0.5 \%$, prevent silting. (2) design side ditch, used for collecting road and slope shed water. When water quantity hours can be used shallow triangular or dish shaped cross section, when the water flow can be with rectangular cross section, in order to prevent the occurrence of traffic accident vehicle traveling to rectangular cross-sectional side ditch, ditch should be provided with a slotted hole cover plate. (3) to set up a ditch, cut off the sink ditch water can be gathered by the side of the ditch side of the ditch to the slope of the ditch. In this way, a large number 
of surface water can be prevented. In addition, you can also set the slope drainage holes, thus discharging fissure water in the slope, enhance the slope stability. (4) a drop chute, etc.. For the easy erosion of the slope will be used to prevent erosion of sand, drainage system in the water to pass through the sand well, as shown in figure. 2.

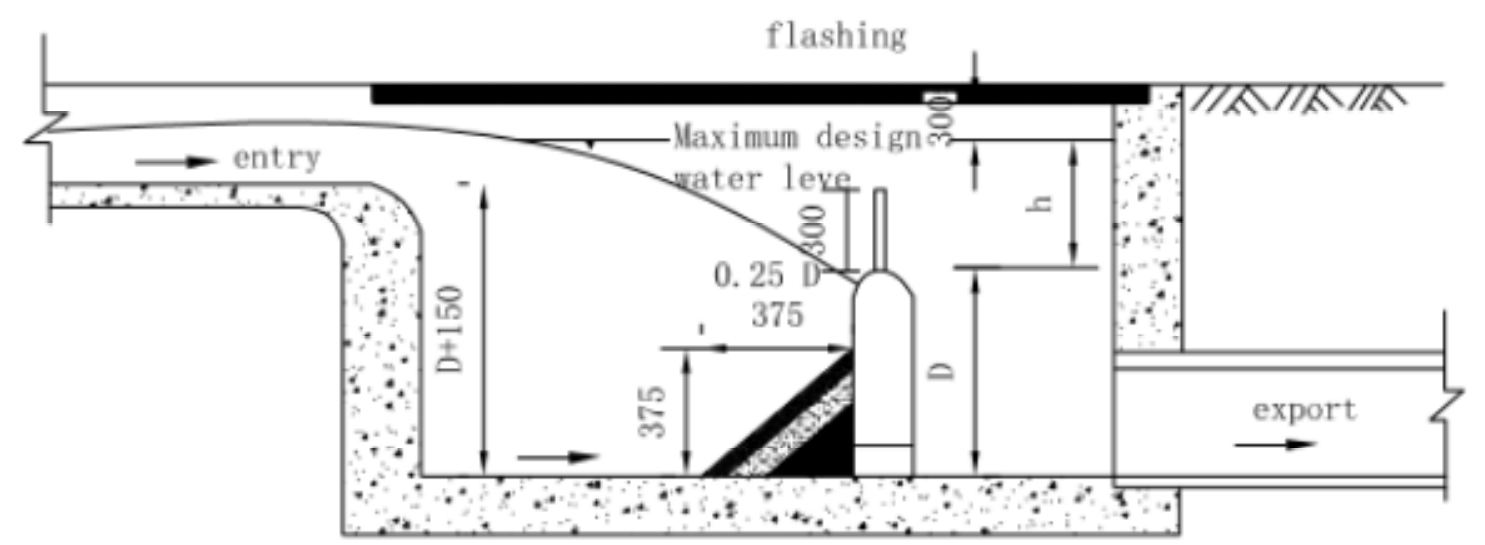

Figure. 2 sand cutting well

In addition, in order to facilitate rapid drainage and drainage, whether it is anchor Ragas structure beam slope or arch skeleton slope protection etc., can be the longitudinal concrete skeleton design into a groove shaped and below the drain hole design guide groove, water drainage to the groove, groove with the exclusion of slope, as shown in Figure 3, 4, 5.

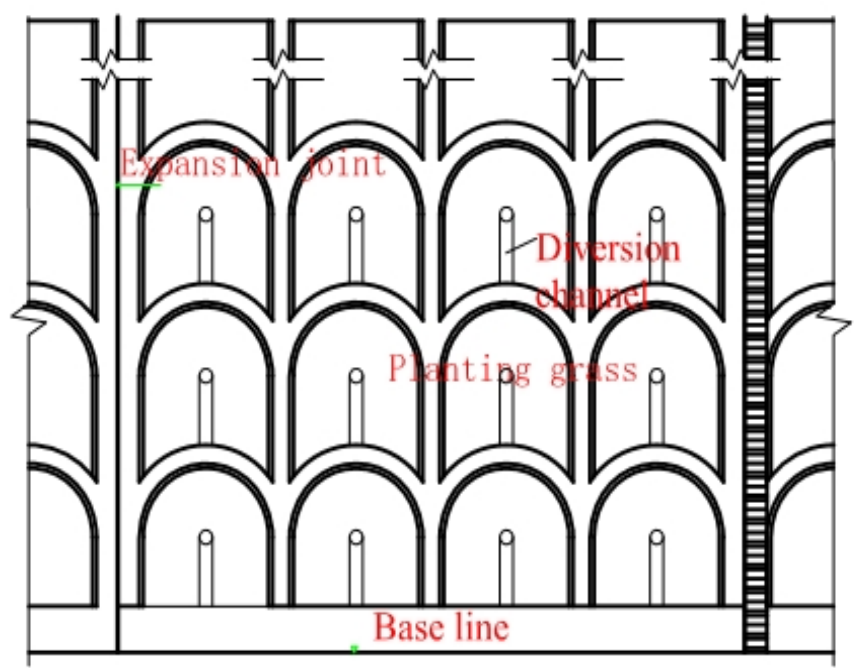

Fig. 3 slope surface of arch frame

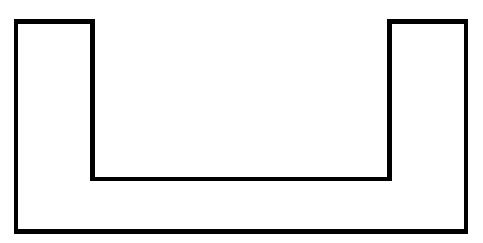

Fig. 4 transverse section of diversion channel

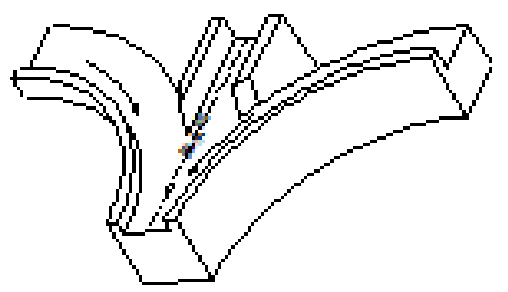

Fig. 5 groove design of longitudinal concrete frame

Underground drainage measures should be considered: Sewer, blind ditch, seepage wells, drainage hole, drainage hole, drainage wells. The sewer ditch wall should be meet the filter layer, the back wall ditch should be set impervious layer, as shown in figure 6. Blind ditch should set the geotextile or granular filter layer to prevent blockage of the drainage blind ditch, influence. 


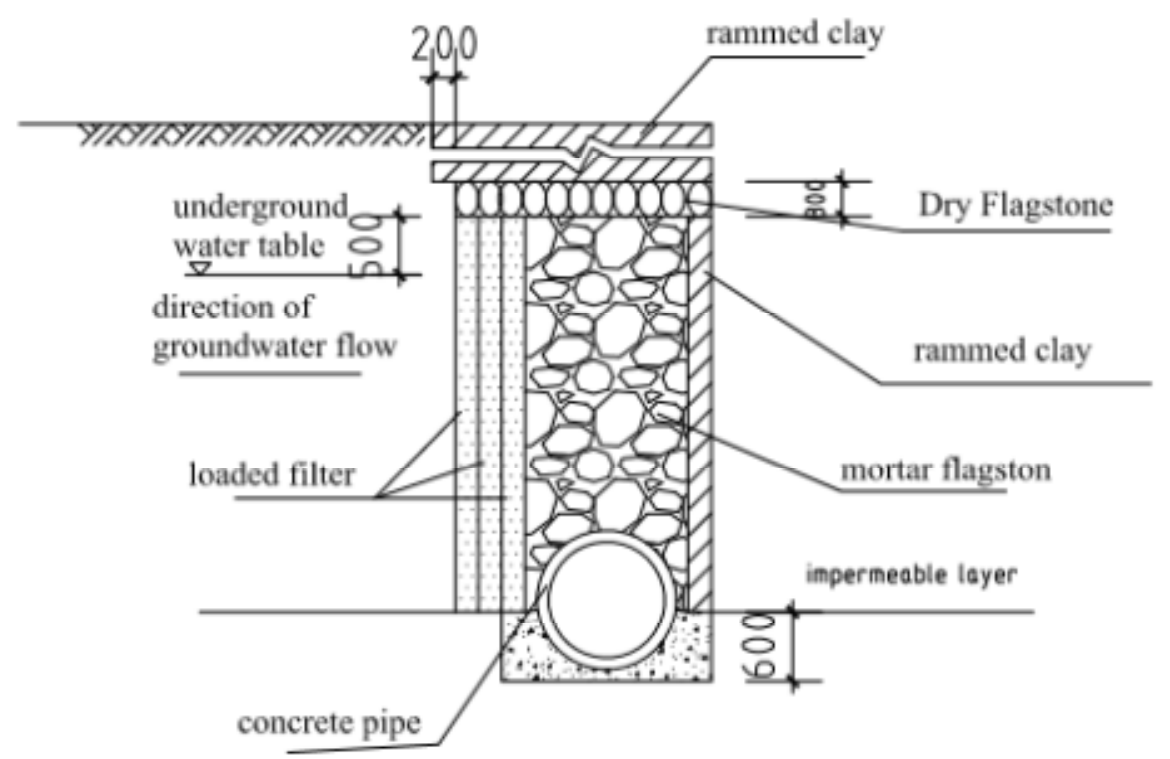

Figure 6 sewer drainage pipe (size: $\mathbf{m m}$ )

\section{Conclusions}

Through the analysis of the reasons of the slope, the slope shape, geological conditions, external environment and other factors are likely to cause slope instability, and many examples show that heavy rainfall or continuous rainfall is the main cause of slope instability. The appropriate slope reinforcement measures combined with effective rapid drainage measures are essential to the stability of the slope.

(1)For retaining wall, retaining wall, a supporting scheme, the drainage measures should be is the combination of ground and underground comprehensive management, and the drainage amount considered to expand a wall soil drainage system should be good measures to prevent clogging.

(2) For prestress anchor cable frame beam, sash anchor a supporting scheme, in combination with the slope surface drainage and underground drainage based on, but also to pay attention to the drainage structure between the connection details, the ditch between the connection is most likely to turbulent flow occurs and blockage of the place. In order to prevent the occurrence of turbulence and splash, can take the buffer wall or sump. For the prevention and control of erosion and sand can be used as well.

\section{Acknowledgements}

This work was financially supported by the science and technology project of Jiangxi Provincial Communications Department (Item number: 2015C0067).

\section{References}

[1] Zhou Weiyi, Peng Heng and Zheng Zuyong. Highway slope comprehensive decision-making [J]. highway, 2003,01:113-117.

[2] Zhang Tao. Ten days of high-speed typical phyllite high slope stability analysis and support design optimization of [D]. Chang'an University, 2013

[3] Xu Weiya, Zhou Jiawen, Shi Chong, Ming Wei Li, Zhao Yi, Wang Xiang Huang, Zheng He. Huashiban Shun layer of rock high slope stability and reinforcement measures [J]. Journal of rock mechanics and engineering, 2008,07:1423-1435.

[4] Bin Jian Tan, Yu Min, Yang, Huang Dingping. Guilin Liuzhou Expressway Slope by prestressed anchor cable reinforcement scheme design [J]. Exploration Engineering (geotechnical drilling and Excavation Engineering), 2010,05:73-77. 
[5] Zhang Congjun. The design and construction of the high voltage tower slope reinforcement design and construction of the high voltage tower of the king slope of Ji Huai Expressway 2012,01:118-121.

[6] Guo Hongjun, Jiang Qing Hui Jin Shan sun. Dagangshan hydroelectric power station on the right bank high slope reinforcement scheme optimization [J]. The people of the Yangtze River, 2012,15:16-19

[7] Fang Qiu Jiang. Fujian Province Zhang (state) - Chao (ANN) motorway A2 contract section of high-voltage tower slope reinforcement engineering design and construction [J]. China Harbour Engineering, 2001,06:49-52.

[8] Chen Xiu and Zhang Hua. Discussion on the design and reinforcement of high slope on the highway of the Mei River [J]. foundation of 2006,01:24-27.

[9] Chen Jianping, Tang Huiming, Liu yourong, Hu Xinli, Wang Liangqing, Zhang Zhibo. Beijing Zhuhai Expressway Dawu section of high slope reinforcement design method [J]. Geology and prospecting, 2000,02:45-48.

[10] Su Zhou Yu. Qingxing highway design on [J]. coal transportation technology consolidation subgrade slope, 2015,03:99-102.

[11]Sun Daolai, Gu Zhijie Zhang Shi highway Baoding section slope protection and reinforcement measures [J]. Hebei traffic science and technology, 2007,02:31-34.

[12]Huang Xiang, Chen Guihua, Liao, Muong khuong. (Ming) - Fu (state) highway K196+425 +640 section of the road graben on the right side of the landslide Governance [J]. Geological disasters in China and prevention journal, 2006,01:1-3+21.

[13]Xu Binglian, Fan Qiuyan, Zhu. The record of the management of the expansive rock and soil landslide in Guangxi [J]. Chinese Journal of rock mechanics and engineering, 2013, S2:3812-3820.

[14] Yang Zhifa, Zhang Luqing, Zhu Jiewang. Chinese Journal of rock mechanics and engineering [J]. four new techniques in slope reinforcement, 2005,21:30-36. 